\title{
Gestão do Conhecimento na análise de falhas: mapeamento de falhas através de sistema de informação
}

\author{
Dagoberto Alves de Almeida \\ Fabiano Leal \\ Alexandre Ferreira de Pinho \\ Liliane Dolores FAgundes \\ Universidade Federal de Itajubá
}

\begin{abstract}
Resumo
O desempenho das empresas em ambientes concorrenciais encontra-se cada vez mais relacionado com a capacidade das empresas em produzir, armazenar e disseminar conhecimento. Esta importância é intensificada quando o conhecimento é usado para a análise de falhas, com o objetivo de evitar a ocorrência de problemas e aumentar a confiabilidade dos sistemas. Dentro deste contexto o presente trabalho apresenta a aplicação da Gestão do Conhecimento para a análise de falhas em uma empresa distribuidora de energia elétrica. $\mathrm{O}$ foco deste artigo é a apresentação de um modelo para mapeamento de falhas e de um sistema de informação que operacionaliza o método. Tal sistema auxilia na construção das árvores de falhas, no armazenamento de documentos, fotos e descrições relacionadas para cada árvore de falhas desenvolvida. Em suma, este trabalho apresenta uma aplicação prática da Gestão do Conhecimento que enseja uma metodologia nova e de uso comprovado.
\end{abstract}

Palavras-chave

Gestão do Conhecimento, Sistemas de Informação, Análise de Falhas.

\section{Knowledge Management in the failure analysis: mapping failure method using information system}

\begin{abstract}
The managerial excellence is based on the company competence to produce, store and disseminate knowledge. Such an importance is even more justified by the use of knowledge to analyze failures in order to avoid undesirable consequences and guarantee the system reliability. In this context, this article presents a Knowledge Management application in an electric energy company. The main aim of this article is to present a method for mapping failures through an information system. This system provides failure trees, which storage photos, procedures, management descriptions of failures and, to avoid relapse, previous ways of solutions. In short, this work provides a practical application of the Knowledge Management approach to the failure analysis subject.
\end{abstract}

\section{Key words}

Knowledge Management, Information System, Failure Analysis. 


\section{INTRODUC̣ÃO}

O presente trabalho tem como propósito o processo de análise de falhas em uma empresa distribuidora de energia elétrica, utilizando para isto um modelo para mapeamento de falhas e um modelo de sistema de informação. A análise de falhas embora seja um tema largamente debatido na literatura relativa à confiabilidade de sistemas, ou mesmo na abordagem da Qualidade Total com os mapas de causa e efeito, ainda apresenta alguns campos de inovação. Por exemplo, este artigo considera a dinâmica dos estágios de conversão do conhecimento com vistas à externalização do conhecimento tácito, individual de cada especialista, em conhecimento explícito, disponível coletivamente para toda a organização. Neste aspecto, o artigo apresenta uma contribuição relevante em termos da aplicação Gestão do Conhecimento em uma empresa do setor elétrico.

A Gestão do Conhecimento vem tendo especial atenção pelas empresas do setor elétrico, haja vista o Seminário Nacional de Gestão da Informação e do Conhecimento no Setor de Energia Elétrica (Sinconee) que se encontra em sua VI edição (www.sinconee.com.br).

Karsak et al. (2002) alertam para o fato que a competitividade global estimulou as empresas a buscarem níveis mais altos de qualidade para seus produtos ou serviços. Desta forma, a análise das falhas representou, em muitos casos, a garantia de sobrevivência das empresas, tamanha é a vigilância e a cobrança da sociedade. Ainda neste sentido, Dikmen et al. (2004) salientam que o sucesso de uma organização depende principalmente de como ela utiliza seus recursos para satisfazer os clientes. Para utilizar os recursos, tanto humanos como técnicos, adequadamente, é necessário primeiramente identificar e analisar os problemas, ou seja, as falhas que existem em determinado bem ou serviço. Mais especificamente, para buscar a solução da consequiência indesejada é necessário atuar a partir de seus fatores causadores.

Segundo Ganim (2003), a gestão de falhas de uma empresa está diretamente ligada ao incremento da produtividade, permitindo a adequada alocação dos recursos em busca de maior qualidade. A própria revisão tarifária solicitada junto ao agente regulador (ANEEL), que estabelece o processo de revisão dos valores das tarifas das empresas que detêm concessão pública para prestar serviço de distribuição de energia elétrica, contempla esta questão. Caso os ganhos de eficiência das distribuidoras sejam maiores que os projetados na revisão, elas poderão se apropriar da diferença entre o resultado estimado e o efetivamente realizado. Em resumo, ao melhorar sua produtividade, as distribuidoras podem aumentar seu ganho financeiro.
Com as empresas do setor de energia elétrica a cobrança pela qualidade dos serviços, além de ser realizada pelos clientes, também é realizada pela Agência Nacional de Energia Elétrica (ANEEL), com base em indicadores cada vez mais rigorosos.

O trabalho em questão tem como objetivo principal apresentar uma metodologia para o mapeamento do processo de formação de falhas em concessionárias de distribuição de energia elétrica. Também é objetivo deste trabalho apresentar um modelo de sistema de informação que auxilie na aplicação da metodologia. Tal sistema de informação contempla a análise de falhas através de diagramas de causa e efeito que foram construídos através de reuniões com funcionários de diversos departamentos da empresa em questão. Este sistema propõe o uso de informações (documentos, descrições, fotos) associadas a cada etapa da árvore de falhas, a fim de possibilitar à organização reconhecer a arquitetura das falhas. A gestão deste conhecimento se aplica a treinamentos e a tomada de decisões, focando evitar a reincidência destas falhas. Por conseguinte, para a análise das falhas foram utilizados o conhecimento e experiência de alguns especialistas, profissionais da própria empresa e também de profissionais da área acadêmica, membros da equipe executora do projeto base desta pesquisa.

Os primeiros itens do trabalho apresentam uma revisão do atual estado da arte com relação à Análise de Falhas, à Gestão do Conhecimento e a Sistema de Informação. Logo em seguida, é apresentado o Modelo de Mapeamento de Falhas, que permite colocar em prática as formas de conversão do conhecimento, as quais são também apresentadas através do modelo de Nonaka e Takeuchi. Para auxiliar na operacionalização de tal metodologia para análise de falhas é proposto um Modelo de Sistema de Informação. Tal modelo e um exemplo de mapeamento (árvore de falha) são apresentados. Para finalizar o artigo, estão as conclusões tiradas com a realização do trabalho.

\section{ANÁLISE DE FALHAS}

A distribuição de energia elétrica, como qualquer outro serviço, pode conter falhas durante sua prestação. No entanto, conforme o destacado por Almeida et al. (2004), falhas mais graves, como a interrupção, podem gerar grandes prejuízos, cuja peculiaridade não é comum a outros tipos de prestações de serviços. O prejuízo aqui mencionado não significa apenas a quantidade de dinheiro que a distribuidora deixa de receber quando a carga é interrompida. Os mesmos autores ainda relatam que a falha pode atingir grandes proporções se afetar indústrias que tenham sua produção comprometida e que possam 
mover processos judiciais, implicando em penalizações financeiras contra a concessionária. Piores ainda são os casos em que as interrupções no fornecimento de energia possam afetar a vida humana, por exemplo, se a energia for interrompida para um hospital ou para a residência de um indivíduo que utilize um aparelho de sobrevida, como um pulmão artificial.

Alguns conceitos são importantes quando é realizada uma análise de falhas. Alguns deles são apresentados a seguir.

Segundo o Comitê de Distribuição (1982), a falha em sistemas de distribuição corresponde a todo evento que produz a perda de capacidade de um componente ou sistema desempenhar sua função, levando-os à condição de operação inadmissível. Dentre as falhas no fornecimento de energia elétrica, a interrupção do fornecimento de energia apresenta alta gravidade e influencia negativamente os índices de continuidade (Almeida $e t$ al., 2004).

De acordo com Rausand e Oien (1996), a falha representa um conceito fundamental para a análise de confiabilidade, sendo a falha definida por estes autores como sendo o término da habilidade de um item para o desempenho de uma requerida função. De acordo com o IEC 50 (1990), International Electrotechnical Commission, a falha é o evento onde a função requerida é interrompida, excedendo os limites aceitáveis, enquanto a falta é o estado de um item caracterizado pela impossibilidade de desempenhar uma requerida função, excluindo as situações de parada por manutenção preventiva (ou ações programadas) e paradas por falta de recursos externos. A falta é, portanto, um estado conseqüente.

Rausand e Oien (1996) relatam que as falhas são sempre classificadas em modos de falhas. Segundo os autores, modo de falha pode ser definido como o efeito pelo qual uma falha é observada em um item que falhou, ou seja, é como nós podemos observar o defeito. Nunes (2001) define modo de falha como sendo a maneira pela qual um determinado item deixa de executar sua função.

Outro conceito importante quando as falhas estão sendo analisadas é a "causa de falhas". De acordo com o IEC 50 (1990), a causa da falha pode ser definida como sendo a circunstância, durante o projeto, manufatura ou uso, na qual tenha conduzido à falha. A causa da falha é parte necessária da informação para evitar a falha ou sua reincidência.

Uma das formas para realizar a análise das falhas é através do mapeamento das mesmas. O mapeamento consiste em ilustrar o processo de formação de falhas. Para o mapeamento de falhas proposto neste artigo, pesquisou-se uma ferramenta de análise causa e efeito que permitiria realizar o mapeamento. Deste modo, três ferramentas foram estudadas: Fault Tree Analysis (FTA), Event Tree Analysis (ETA) e o Diagrama de Árvore ou Diagrama Sistemático.

A primeira técnica estudada com o objetivo de auxiliar no mapeamento foi a Fault Tree Analysis (FTA). De acordo com Hammarberg e Nadjm-Tehrani (2003), a FTA é um modelo gráfico que parte de um modo de falha denominado "evento de topo", buscando as causas diretas da ocorrência do evento. A FTA possibilita também a estimativa de probabilidade com que determinada falha pode ocorrer, ou seja, realiza uma análise quantitativa. Apesar desta ferramenta ter se mostrado conveniente para encontrar as causas que desencadeavam o processo de formação de falhas, a pesquisa teve continuidade para verificar a existência de outras técnicas de causa e efeito que pudessem auxiliar na etapa de diagramação e posterior seleção da mais adequada.

\section{A causa da falha é parte necessária da informação para evitar a falha reincidência.}

A segunda ferramenta que pareceu adequada foi a Event Tree Analysis (ETA). Segundo Alberton (1996), na ETA desenvolve-se um esboço da estrutura da análise de eventos com cenários de perigo, sendo bastante semelhante à FTA, mas enquanto esta última apresenta uma árvore lógica orientada verticalmente, a ETA é orientada horizontalmente. Uma outra diferença da ETA em relação à FTA é que na ETA, durante a diagramação, são utilizadas as possibilidades de amortecer o evento inicial. Nesta técnica também pode ser calculada a probabilidade de ocorrência de determinado evento.

A terceira ferramenta de análise de causa e efeito pesquisada foi o Diagrama Sistemático de Causa e Efeito, uma das Sete Novas Ferramentas da Qualidade. Este diagrama permite mapear toda a série de acontecimentos que devem ocorrer para que determinada falha ocorra. Devido à simplicidade de sua utilização e do mesmo atender o objetivo da diagramação, ele foi selecionado para esta etapa do trabalho. Vale ressaltar que o objetivo é realizar uma análise qualitativa, e não quantitativa, o que justifica a não adoção da FTA ou da ETA.

Durante a pesquisa para seleção de uma ferramenta para a diagramação teve-se contato com as Sete Novas Ferramentas da Qualidade. Dentre estas ferramentas o Diagrama de Afinidades foi identificado como instrumento útil para auxiliar na padronização das falhas, uma 
vez que através dele é possível organizar dados de acordo com a relação natural entre os mesmos.

Como o Diagrama de Afinidade e o Diagrama de Árvore foram ferramentas selecionadas para a realização do trabalho, são mostrados mais detalhadamente nos subitens a seguir.

\section{Diagrama de Afinidade}

O Diagrama de Afinidade, segundo Mizuno (1993), esclarece problemas ou situações importantes, cujo estado inicial é confuso, desordenado ou inexplorado. Karsak et al. (2002) esclarece que em coletas de dados verbais sobre determinado problema, o Diagrama de Afinidade permite o agrupamento dos mesmos em diversos conjuntos segundo suas afinidades e relações naturais. Deste modo, consegue-se uma maior compreensão da situação e sua consideração sob novos enfoques, estimulando a criatividade e o surgimento de novas idéias.

De acordo com He et al. (1996) e Anjard (1995), o Diagrama de Afinidade é uma ferramenta de brainstorming, utilizada para agrupar fatos, opiniões, idéias, de acordo com alguma forma de afinidade natural. Esta ferramenta coleciona um grande número de idéias, opiniões, informações e organiza estes dados, agrupando através de um relacionamento natural entre cada item.

A idéia do Diagrama de Afinidades converge para o trabalho em equipe, já que o problema de organização de idéias aparece quando várias pessoas se manifestam sobre um mesmo tema. O processo de agrupamento é lento, pois é preciso captar a essência de cada uma das idéias, em cada um dos dados. É, portanto, conveniente que se esteja bem seguro de que o tema é adequado a esse tipo de trabalho. Esta atividade de agrupamento está representada na Figura 1.

Um mesmo evento pode ser definido por diversos nomes $\mathrm{a}_{\mathrm{i}}(\mathrm{i}=1$ até $\mathrm{n})$ pelos departamentos, conforme mostra a figura 1. Compete à equipe definir o evento e nomeá-lo por um nome padrão (falha A). Definidas as falhas, estas são então agrupadas de acordo com suas afinidades (grupo C, contendo a falha A e B).

No trabalho realizado, as falhas foram agrupadas em Grupos de Falhas, assim como foram criados Origens de Causas. Esta questão será discutida no item "Modelo de Mapeamento de Falhas", do presente artigo.

\section{Diagrama de Árvore}

A apresentação da falha, no presente trabalho, e seu encadeamento lógico com suas causas se dão através do Diagrama de Árvore. De acordo com He et al. (1996) e Karsak et al. (2002), o Diagrama de Árvore ou Diagrama Sistemático é utilizado de maneira top-down, para detalhar uma falha em sucessivos níveis.

O Diagrama de Árvore representa acontecimentos na forma de uma árvore e seus galhos. De acordo com Mizuno (1993), quando se seleciona os meios para alcançar uma meta, é necessário estabelecer os meios secundários para este fim; então os meios principais se tornam as metas dos meios secundários. Este comportamento demonstra a dualidade dos componentes intermediários da árvore.

Figura 1: Diagrama de afinidades utilizado no agrupamento de falhas afins.

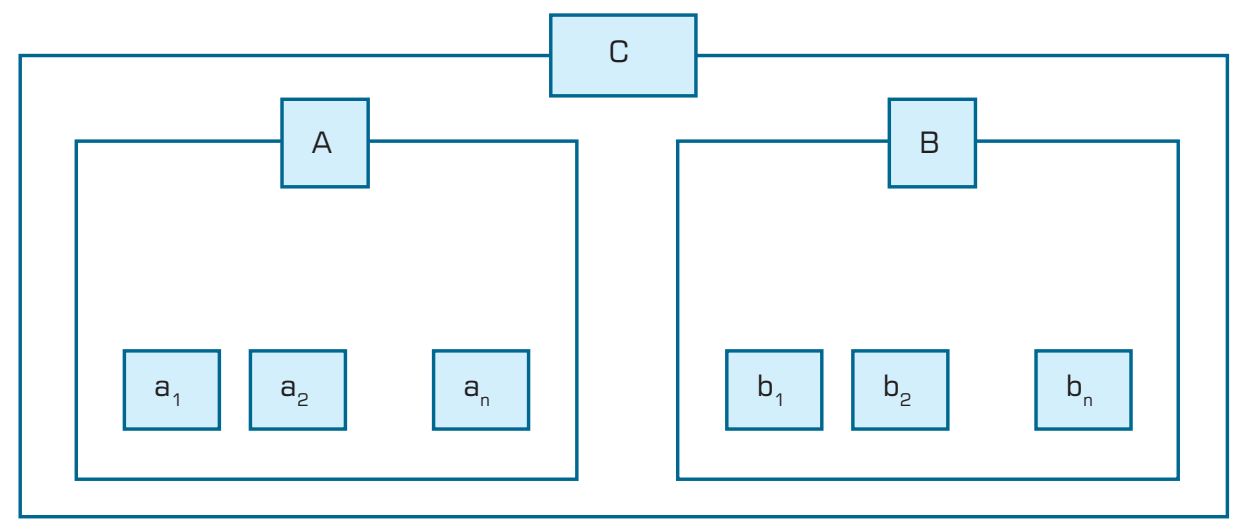

Fonte: Almeida et al., 2004b. 
O uso de um diagrama de causa e efeito (Diagrama de Ishikawa, ou "espinha de peixe") é simples e eficaz, porém apresenta algumas dificuldades, sobretudo quando existe um número elevado de causas. Nestes casos, uma possível solução é ordenar as causas e os efeitos na forma de um Diagrama de Árvore. Este diagrama, que expressa as causas e seus efeitos é denominado Diagrama Sistemático de Causa e Efeito, e será utilizado neste trabalho.

Como será mostrado no decorrer do trabalho, estas ferramentas auxiliarão durante a prática de Gestão do Conhecimento na empresa em questão.

\section{GESTÃO DE CONHECIMENTO}

\section{Considerações iniciais}

Segundo Sveiby (1998), a Gestão do Conhecimento (GC) pode ser entendida, basicamente, como "a arte de gerar valor a partir de bens intangíveis da organização". Adams e Freeman (2000) definem GC como a gestão que encara conhecimento como algo construído ativamente em um ambiente social. Outra possível definição para a GC pode ser apresentada como o conhecimento coletivo de uma organização, e não apenas estoque de dados ou informações. Este conhecimento coletivo inclui experiências, habilidades, dados e informações (SHOCKLEY III, 2000). Já Silveira (2004) cita que a "Gestão do Conhecimento é, antes de tudo, uma nova forma de se trabalhar, uma nova cultura organizacional, na qual o ambiente e os valores permitam gerar a motivação necessária à aprendizagem, ao compartilhamento ou mesmo à transferência e à aplicação do conhecimento."

Xu e Quaddus (2005) alertam para o fato que a mudança de uma economia baseada em recursos para uma economia baseada em conhecimento está fazendo com que as organizações voltem suas atenções para o gerenciamento e a maximização do mais importante bem que elas possuem: o conhecimento. Ainda neste sentido, Laudon e Laudon (2004) afirmam que na economia da informação, competências essenciais baseadas em conhecimento são patrimônio-chave da organização. Fabricar produtos ou serviços exclusivos ou produzi-los a custo mais baixo que os concorrentes baseia-se em conhecimento superior dos processos de produção. Saber como fazer coisas eficazes e eficientemente, utilizando métodos que outra organização não consiga copiar, é fonte primária de lucro e fator de produção que não pode ser comprado em mercado externo.

À medida que o conhecimento se torna um patrimônio essencial e estratégico, o sucesso organizacional depende cada vez mais da capacidade da empresa de produzir, reunir, armazenar e disseminar conhecimento. Como alertado por Srdoc et al. (2005), a qualidade de qualquer produto ou serviço depende significativamente do conhecimento. Isto significa que através do conhecimento as empresas tornam-se mais eficazes e eficientes na utilização que fazem de seus escassos recursos. Por outro lado, sem conhecimento tornam-se menos eficientes e eficazes no emprego de seus recursos e, por fim, fracassam.

\section{Conhecimento tácito e conhecimento explícito}

Nonaka e Takeuchi (1997) classificaram o conhecimento humano em dois tipos: conhecimento tácito e conhecimento explícito. De acordo com estes autores o conhecimento tácito corresponde a conhecimento pessoal embutido em experiência individual e envolve fatores intangíveis como crenças pessoais, perspectivas e o sistema de valores, ou seja, é um componente crítico do comportamento humano. Os mesmos autores ainda definem conhecimento explícito como sendo o conhecimento que pode ser articulado em linguagem formal, o que inclui sentenças gramaticais, expressões matemáticas, especificações e manuais.

\section{o sucesso organizacional depende cada vez} mais da capacidade da empresa de produzir, reunir, armazenar e disseminar conhecimento.

\section{Formas de conversão do conhecimento}

Nonaka e Takeuchi (1997) ainda citam a existência de quatro formas de conversão do conhecimento: socialização, externalização, combinação e internalização.

- Socialização (de tácito para tácito): é o processo através do qual experiências são compartilhadas e o conhecimento tácito ou modelos mentais e habilidades técnicas são criados. Na prática da vida das empresas um indivíduo poderia adquirir conhecimento tácito de algum colega até mesmo sem o uso da linguagem, usando de imitação, observação e prática, através de treinamento no local de trabalho, sessões informais, brainstorms e interações com os clientes.

- Externalização (de tácito para explícito): este modo de conversão permite a criação de novos e explícitos conceitos. Envolve, no caso das empresas japonesas, a articulação do conhecimento tácito em explícito através do uso 
freqüente de metáforas, analogias, conceitos, hipóteses e modelos. Esta prática seria importante por facilitar a comunicação dos conhecimentos tácitos que, normalmente, são de difícil verbalização. A própria escrita é um ato de conversão de externalização. Leite (2001) alerta para o fato que geralmente ao externalizar usa-se de expressões inadequadas, inconsistentes e insuficientes. No entanto, tais discrepâncias e diferenças entre imagens e expressões promovem reflexão e interação entre indivíduos.

- Combinação (de explícito para explícito): este seria o processo preferido no Ocidente, na medida em que se baseia na troca de informações explícitas e no paradigma da tecnologia de informação. Envolve, pois, bastante o uso de mídias como documentos, reuniões formais, conversas telefônicas e, também, o de redes computadorizadas. Leite (2001) cita como exemplos deste tipo de conversão de conhecimento o caso do ensino em escolas, cursos de MBA e treinamentos.
- Internalização (de explícito para tácito): este último método seria semelhante ao do "learning by doing" em que os membros da organização passariam a vivenciar o resultado prático do novo "conhecimento", ou seja, desenvolveriam um conhecimento operacional.

\section{Modelo de cinco fases do processo de criação do conhecimento organizacional}

Como o presente trabalho reúne um grupo de especialistas com o objetivo de criar conhecimento organizacional é interessante mostrar aqui o modelo que Nonaka e Takeuchi (1997) desenvolveram para o processo de criação do conhecimento organizacional.

O modelo, mostrado na Figura 2, é composto de cinco fases: (a) Compartilhamento do conhecimento tácito; (b) Criação de conceitos; (c) Justificação dos conceitos; (d) Construção de um arquétipo; (e) Difusão interativa do conhecimento.

Figura 2: Modelo de cinco fases do processo de criação do conhecimento organizacional.

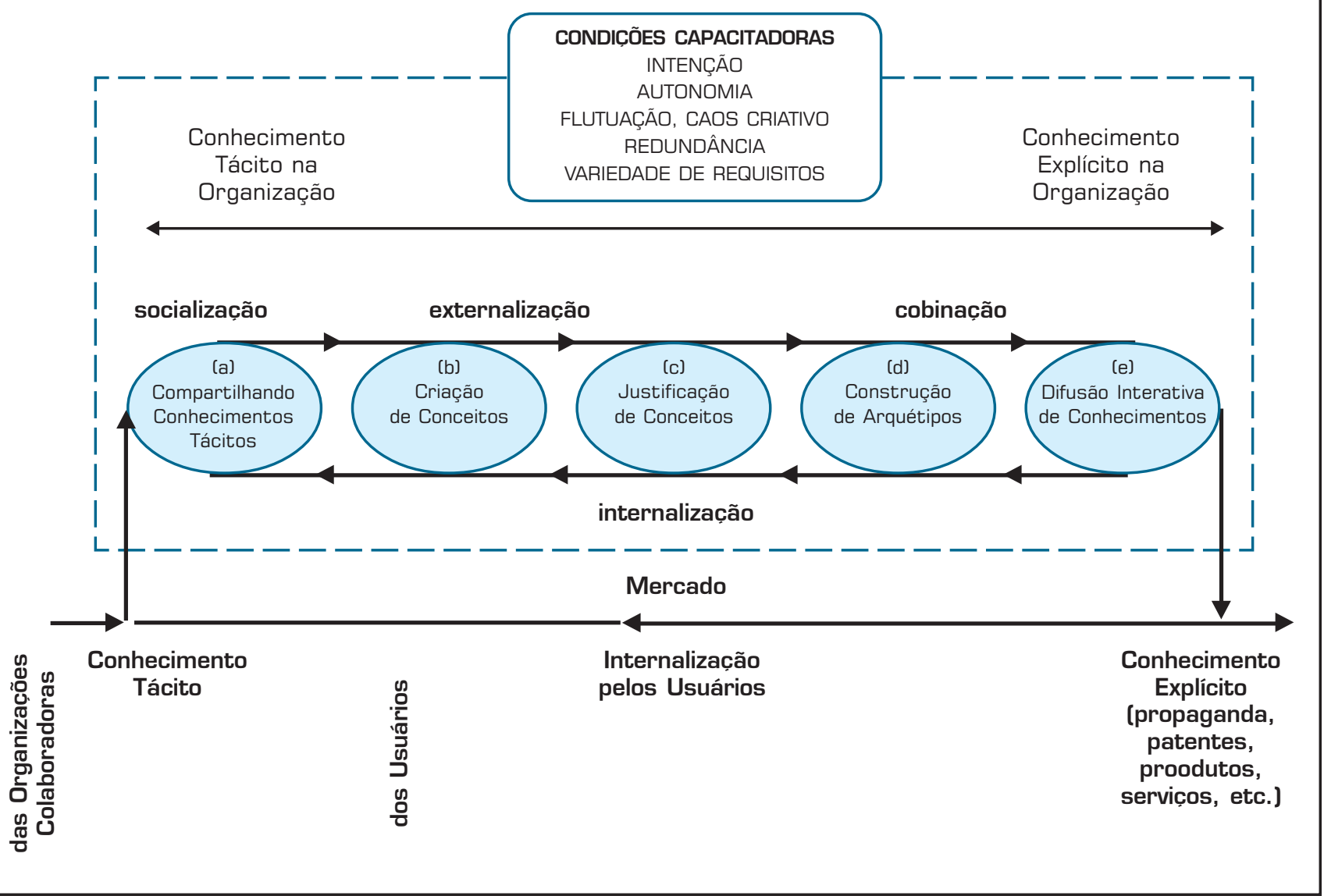

Fonte: Nonaka e Takeuchi (1997). 
O modelo mostrado na Figura 2 tem início com o compartilhamento do conhecimento de cada indivíduo que precisa ser amplificado para toda a organização. $\mathrm{O}$ segundo passo do modelo consiste na conversão do conhecimento compartilhado em conhecimento explícito na forma de um novo conceito. A terceira fase tem por objetivo justificar o novo conceito e determinar se realmente vale a pena perseguir o novo conceito. Na quarta fase, se aprovados, os conceitos são convertidos em um arquétipo, que pode assumir a forma de um protótipo no caso do desenvolvimento de um produto "concreto" ou em um mecanismo operacional no caso de inovações "abstratas". Finalmente, a última fase amplia o conhecimento criado, por exemplo, em uma divisão, a outras divisões ou até a componentes externos, constituindo a difusão interativa do conhecimento.

\section{Gestão do Conhecimento \\ e Tecnologia da Informação}

Apesar da troca de conhecimento não ser algo comum nas empresas, o processo de codificar e transmitir conhecimentos já é uma tradição. Exemplo disto são os programas de treinamento e desenvolvimento, as políticas organizacionais, os relatórios e os manuais (LEITE, 2001). Mas conforme o mencionado por Alavi e Leider (1999) o que é novo na área de gestão do conhecimento é o potencial de utilizar tecnologias de informação modernas. Fato também abordado por Silveira (2004): "A tecnologia da informação possibilita que o conhecimento de uma pessoa ou de um grupo seja extraído, estruturado e utilizado por outros membros da organização e por seus parceiros de negócios, no mundo todo. A tecnologia ajuda também na codificação do conhecimento e, ocasionalmente, até mesmo em sua geração." Desta forma, podemos resumir que os sistemas de informação podem promover aprendizagem organizacional capturando, codificando e distribuindo tanto o conhecimento explícito quanto o tácito. Uma vez que a informação tenha sido coletada e organizada em um sistema, pode ser utilizada muitas vezes. $\mathrm{O}$ conhecimento pode ser preservado como memória organizacional, para treinar futuros funcionários ou ajudá-los no processo de decisão.

A tecnologia da informação tem papel importante na Gestão do Conhecimento, como habilitadora de processos de negócios que visam criar, armazenar, disseminar e aplicar conhecimento. É exatamente dentro deste contexto que surge o Knowledge Management Systems (KMS). Xu e Quaddus (2005) caracterizam o KMS como sendo uma maneira mais eficiente e sistemática de gerenciar conhecimento, que envolve a utilização de tecnologia de informação e outros recursos organizacionais para gerenciar o conhecimento estrategicamente.

\section{SISTEMA DE INFORMAC̣ÃO}

Sistema de informação (SI) é o processo de transformação de dados em informações que são utilizados na estrutura decisória da empresa. Segundo Laudon e Laudon (2004), um SI pode ser definido como um conjunto de componentes inter-relacionados para coletar, recuperar, processar, armazenar e distribuir informação com a finalidade de facilitar o planejamento, o controle, a coordenação, a análise e o processo decisório em empresas e organizações. Estes sistemas têm como atividades básicas: entrada, processamento e saída.

$\mathrm{Na}$ atividade de entrada, são captados dados de fora ou de dentro da organização e estes são colocados diretamente em um sistema de computadores. Dado é qualquer elemento identificado em sua forma bruta que por si só não conduz a uma compreensão de determinado fato ou situação (O'BRIEN, 2001).

\section{A filosofia do presente projeto é entender como "causa" aquilo que plausível de intervenção gerencial.}

Esses dados são organizados, analisados e manipulados através de cálculos, comparação, resumos e classificação, objetivando uma forma de disposição mais significativa e útil na fase do processamento.

Em seguida, na atividade de saída, são transmitidas as informações e os resultados do processamento a locais onde serão usados para tomada de decisão. Define-se informação como o significado que o homem atribui a um determinado dado por meio de convenções e representações (LAUDON \& LAUDON, 2004). Toda informação, portanto, deve gerar uma decisão, que, por sua vez, desencadeará uma ação. A informação constitui-se em suporte básico para toda atividade humana e todo o nosso cotidiano é um processo permanente de informação. No caso das organizações, conhecer seus problemas, buscar alternativas para solucioná-los, atingir metas e cumprir objetivos requer conhecimento e, portanto, informação.

O software de mapeamento de falhas, especificamente desenvolvido para auxiliar o processo de mapeamento, na dinâmica do grupo de trabalho, será apresentado nos tópicos seguintes.

No próximo item inicia-se a exposição da metodologia utilizada no desenvolvimento do presente trabalho. 


\section{METODOLOGIA}

Este tópico contextualizará a pesquisa em questão de acordo com diferentes formas de classificação. Segundo Silva e Menezes (2002), as formas de classificar uma pesquisa são: quanto aos procedimentos adotados; quanto à natureza; quanto à forma de abordagem; e quanto aos objetivos.

O procedimento metodológico utilizado foi a pesquisa-ação. Coughlan e Coghlan (2002) caracterizam a pesquisa-ação como sendo o método no qual o investigador torna-se parte do ambiente estudado com o objetivo de resolver problemas organizacionais. Segundo os mesmos autores, a pesquisa-ação é um método de pesquisa que tem como objetivos tomar ação sobre algum fato e ao mesmo tempo criar conhecimento sobre esta ação. Para facilitar na condução da pesquisa-ação foi utilizado o modelo de mapeamento mostrado na Figura 3, e para a concretização de cada um dos passos do modelo foram utilizados os seguintes instrumentos de coleta de dados: a observação direta, a pesquisa direta a documentos e dados da empresa e entrevistas durante as reuniões com os especialistas para mapeamento das falhas.

Quanto à sua natureza, esta pesquisa se caracteriza como aplicada, que, segundo Silva e Menezes (2002), gera conhecimentos e soluções para problemas específicos.

Em relação à forma de abordagem, esta pesquisa se classifica como qualitativa. Para Glazier e Powell (1992) a melhor maneira de entender o que significa pesquisa qualitativa é determinar o que ela não é. Deste modo, os autores definem que ela não é um conjunto de procedimentos que depende fortemente de análise estatística para suas inferências ou de métodos quantitativos para a coleta de dados.

Quanto aos objetivos, Gil (1996) segue uma classificação embasada em três modalidades: exploratória, descritiva e explicativa. Desta forma, entende-se a presente pesquisa, de acordo com a classificação de Gil (1996), como exploratória, pois tem por característica aprofundar idéias ou, ainda, novas descobertas acerca do assunto.

O próximo tópico apresentará o modelo que ilustra a maneira como os trabalhos de campo da pesquisa foram conduzidos.

\section{MODELO DE MAPEAMENTO DE FALHAS}

Srdoc et al. (2005) reforçam em seu estudo a importância de capturar o conhecimento dentro de uma organização para aumentar a qualidade do produto ou serviço fornecido por ela. No caso deste trabalho, o conhecimento foi capturado através de um modelo de mapeamento de falhas. A Figura 3 apresenta o modelo desenvolvido e utilizado para o mapeamento de falhas. Este mapeamento apresenta como resultado as árvores de falhas com os nós (partes constituintes das árvores representadas por círculos) padronizados e parametrizados.

Conforme ilustrado no diagrama de etapas da Figura 3, o modelo está assim dividido:

a) Formação da equipe

O mapeamento de falhas constitui um trabalho de equipe envolvendo pesquisadores da área acadêmica e também membros da própria organização. Este grupo foi composto por cinco especialistas que trabalham em diferentes setores da empresa e uma equipe da Unifei (membros da Engenharia Elétrica e da Engenharia de Produção). Foi exigido que estes funcionários fossem de áreas diferentes, pois a intenção era a obtenção de diagramas com descrições bastante amplas do tema. Portanto, foi conveniente a formação de uma equipe multidisciplinar e multidepartamental. Foram realizados 12 encontros ao longo de 6 meses, durante o ano de 2004.

b) Conceituação de "falha" e "causa"

Após a formação da equipe, tornou-se necessário esclarecer aos membros da equipe os conceitos de falha e causa, para evitar problemas do mau uso das duas expressões. Esta etapa foi fundamental para a construção da lógica da árvore.

\section{c) Padronização de falhas}

Para o levantamento das falhas e suas causas foram realizados brainstormings com os membros do grupo. Conforme o descrito por Almeida et al. (2004a), inicialmente a equipe através de um diagnóstico definiu as falhas do processo. Logo após, com a finalidade de agrupar falhas que apresentam impactos semelhantes para o consumidor, foram criados quatro Grupos de Falhas: Interrupção do Fornecimento de Energia, Grupo IP (Iluminação Pública), Qualidade Técnica da Energia, Qualidade do Atendimento. Isto significa que todas as falhas que ocasionam interrupção no fornecimento de energia elétrica, por exemplo, foram agrupadas no primeiro grupo. Todas as que estão relacionadas com problemas na iluminação pública se concentram no segundo grupo. As falhas que afetam a qualidade técnica da energia, como oscilações de tensão, se concentram no terceiro grupo. Finalmente, todas as falhas relacionadas com deficiências no atendimento aos clientes foram agrupadas no quarto grupo. A Figura 4 mostra o Diagrama de Afinidades obtido nesta etapa.

A padronização, mais do que a montagem de grupos, significou a criação de uma semântica da falha (nome e descrição).

Fagundes e Almeida (2005) e Fagundes (2005) rela- 
Figura 3: Modelo de mapeamento de falhas.

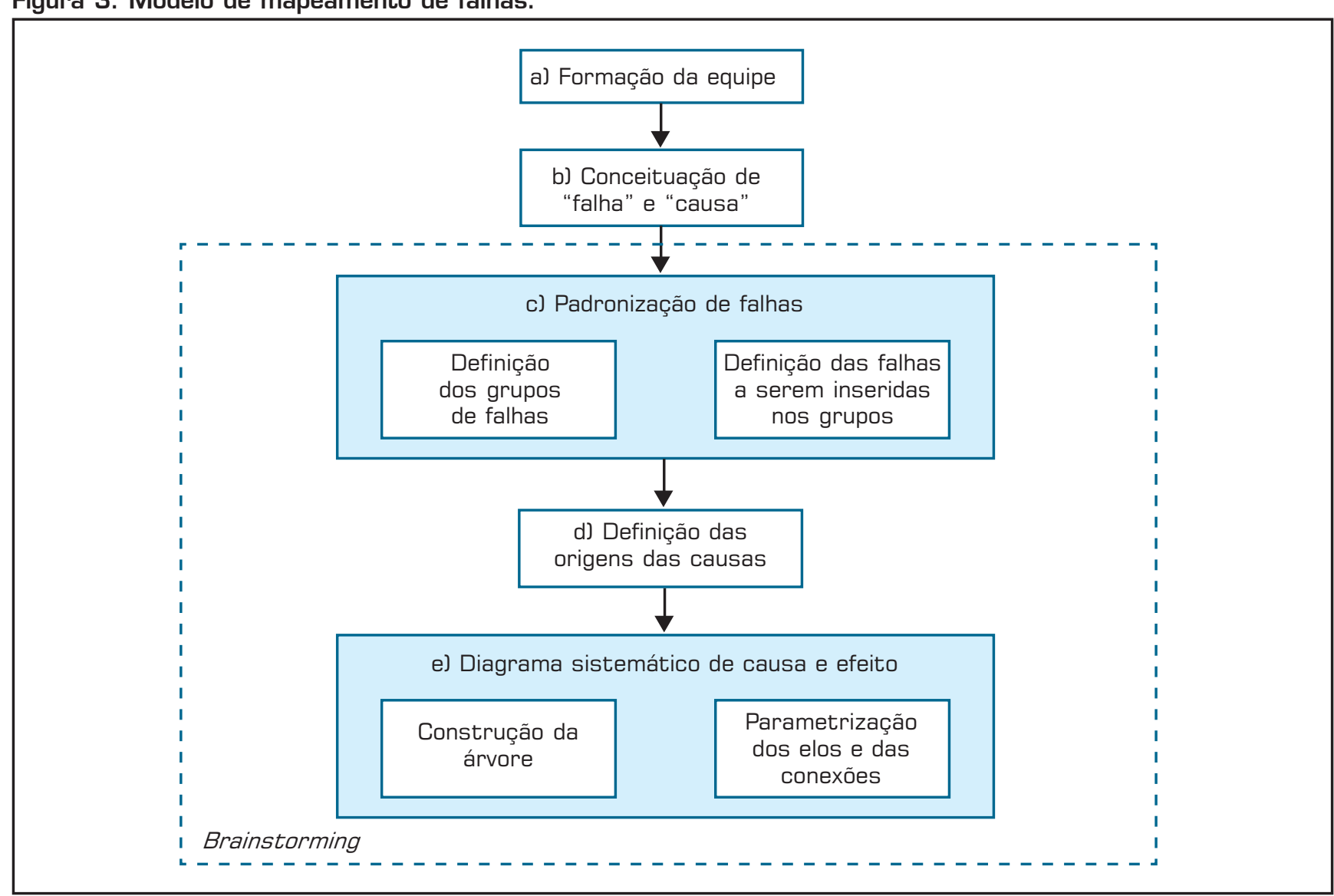

Fonte: Almeida et al., 2004b.

Figura 4: Diagrama de Afinidade das principais falhas diagnosticadas.

\section{GRUPO INTERRUPÇÃO DO FORNECIMENTO DE ENERGIA}

1. Abertura de chave fusível

2. Atuação do disjuntor

3. Atuação do religador da subestação

4. Cabo interrompido

5. Interrupção do suprimento externo

6. Manobra inadequada

7. Pára-raio aberto

8. Problema interno no cliente

9. Problemas de isolação

10. Problemas nas conexões

11. Transformador de distribuição danificado

\section{GRUPO QUALIDADE DO ATENDIMENTO}

1. Deficiência da comunicação institucional

2. Deficiência da equipe de campo

3. Deficiência do Call-Center

4. Deficiência no posto de atendimento

\section{GRUPO ILUMINAÇÃO PÚBLICA (IP)}

1. Atraso no atendimento da solicitação de IP

2. Baixa luminosidade

3. Lâmpada acesa durante o dia

4. Lâmpada apagada

5. Luminária danificada

6. Ruídos de componentes da IP

\section{GRUPO QUALIDADE TÉCNICA DA ENERGIA}
1. Cintilação
2. Desequilíbrios
3. Harmônicos de tensão
4. Interrupções de curta duração
5. Variação de tensão
6. Variação momentânea de tensão

Fonte: Fagundes e Almeida (2005). 
tam que nesta fase inicial houve a utilização de três formas de conversão do conhecimento: socialização, externalização e combinação. A socialização ocorreu através das sessões de brainstorming. Os funcionários relataram nestas sessões as falhas mais ocorridas em cada setor de acordo com a experiência de cada um. A combinação ocorreu principalmente através da utilização dos documentos existentes na empresa e que de alguma forma traziam registros referentes às falhas ocorridas. Também a combinação ocorreu devido a reuniões formais. $\mathrm{O}$ registro de todas as informações adquiridas nas sessões de brainstorming, nos documentos e nas reuniões formais, que geraram a Figura 4, implicou no uso da externalização.

\section{d) Definição das origens das causas}

Ainda utilizando a idéia do Diagrama de Afinidades, foram definidas as origens das causas. As origens são grupos, com características afins, que originam todos os efeitos subseqüentes, até a conseqüência final, a falha.

Esta definição permite criar uma convergência dos ramos da árvore até as origens padronizadas de causas. $\mathrm{O}$ Quadro 1 representa as origens definidas.
Cada origem apresenta características comuns entre as causas, apresentando, portanto, similaridades nas intervenções gerenciais.

Fagundes (2005) e Fagundes e Almeida (2005) citam que nesta etapa também ocorreram as seguintes formas de conversão do conhecimento: socialização, externalização e combinação. A socialização ocorreu através das sessões de brainstorming. Os funcionários expuseram as origens que desencadearam o processo de formação das falhas mais ocorridas, de acordo com a experiência de cada um. A combinação ocorreu através da utilização dos documentos existentes na empresa e que de alguma forma traziam registros referentes à origem das falhas. Também a combinação ocorreu devido a reuniões formais. O registro de todas as informações adquiridas nas sessões de brainstorming, nos documentos e nas reuniões formais, que geraram a Tabela 1 , caracteriza o uso da externalização.

e) Diagrama Sistemático de Causa e Efeito

Como mencionado anteriormente, três técnicas de análise de causa-efeito foram pesquisadas para verificação da eficácia na etapa de diagramação: a Fault Tree

\section{Quadro 1: Agrupamento em origens de causas e descrições.}

\begin{tabular}{|c|c|}
\hline ORIGENS & DESCRIÇÃO \\
\hline Programada & Não obediência aos prazos de programação de desenvolvimento da atividade. \\
\hline Fenômenos naturais & Tempestades, descargas atmosféricas, inundações, ventania, temperatura, umidade. \\
\hline Meio ambiente & $\begin{array}{l}\text { Animais diversos linterrupção em linhas aérea e subterrânea), erosão, árvore, poluição, } \\
\text { queimadas. }\end{array}$ \\
\hline Externa ao sistema & $\begin{array}{l}\text { Suprimento de energia à concessionária (Sistema de Geração e Transmissão), instalação } \\
\text { do cliente. }\end{array}$ \\
\hline Fator Humano & Não obediência aos procedimentos e normas vigentes (concessionária, cliente e terceirizados) \\
\hline Vandalismo & $\begin{array}{l}\text { Ato intencional e danoso, provocado por terceiros. Ex: tiro no isolador, artefatos enrolados } \\
\text { na rede (calçados, arame, etc.). }\end{array}$ \\
\hline Fraude & $\begin{array}{l}\text { Adulteração nos ativos da empresa. Ex: roubo de energia, fornecimento ou instalação de } \\
\text { material não conforme. }\end{array}$ \\
\hline Furto & Apropriação ilícita de ativos da empresa. Ex: roubo de cabos. \\
\hline Procedimentos & Procedimentos (comissionamento, etc.) e projetos inadequados. \\
\hline Operacional & Decorrentes dos testes de pesquisa de defeitos, manobras na rede, etc. \\
\hline Acidentes & Pipa, asa-delta, pára-quedas, abalroamentos, etc. \\
\hline Comunicação & $\begin{array}{l}\text { A empresa não orienta adequadamente seus consumidores sobre interrupção programada } \\
\text { e não implementa programas de conscientização. }\end{array}$ \\
\hline Interna & $\begin{array}{l}\text { Decorrente de causas relativas à deterioração dos componentes da rede (defeito interno } \\
\text { do próprio componente já instalado e em operação]. }\end{array}$ \\
\hline $\begin{array}{l}\text { Contingência do } \\
\text { sistema }\end{array}$ & $\begin{array}{l}\text { Indisponibilidade de parte do sistema, tal como: indisponibilidade de linha, gerador, } \\
\text { transformador, etc. }\end{array}$ \\
\hline
\end{tabular}

Fonte: Almeida et al. (2004b). 
Analysis (FTA), a Event Tree Analysis (ETA) e o Diagrama Sistemático de Causa e Efeito. Esta última foi a selecionada para a realização da diagramação, por motivos explicados no item "Análise de Falhas" do presente trabalho.

Através desta etapa foi possível o desenvolvimento de diagramas que ilustram a arquitetura do processo de formação das falhas.

Quanto à construção do Diagrama Sistemático de Causa e Efeito, pode-se dizer que este se caracterizou por um processo trabalhoso e lento. Sua construção foi evolutiva, isto é, acompanhou a evolução da equipe no entendimento do tema.

O Diagrama Sistemático de Causa e Efeito, utilizado neste trabalho, apresenta um comportamento dual dos nós. Cada nó intermediário (meio da árvore) assume um papel de causa/efeito. O nó inicial (cabeça da árvore) apresenta identidade única, de falha (efeito). Os nós finais (pés das árvores) também apresentam uma identidade única, de causa, conforme mostra a Figura 5.
Cada nó da árvore e suas conexões foram então parametrizados, sendo caracterizados por um conjunto de informações. Importante salientar que apenas nos nós finais foram parametrizadas as origens. Deve-se destacar ainda que a análise do gestor ocorreu da cabeça da árvore para os pés da árvore. A atuação gerencial seguirá em sentido contrário.

Cada nó da árvore, seja o nó falha (cabeça da árvore), os nós causa/efeito (meio da árvore) ou os nós causa (pés da árvore), foram parametrizados com informações padrões, tais como mostrado na Figura 5:

i) nó falha $(\mathrm{F})$

Nos nós falha foram definidos o seu código (i), nome e descrição, o grupo ao qual pertence (conforme mostra Figura 4) e os seguintes fatores:

- Fator Potencial de Dano $\left(\mathrm{G}_{\mathrm{i}}\right)$ : fator que representa o potencial de dano da falha ao sistema, variando de 1 (menor dano) a 9 (maior dano). O potencial de dano registra uma característica intrínseca da falha.

Figura 5: Lógica da arquitetura das árvores, apresentando a relação dual dos nós (meio da árvore) e a parametrização dos nós.

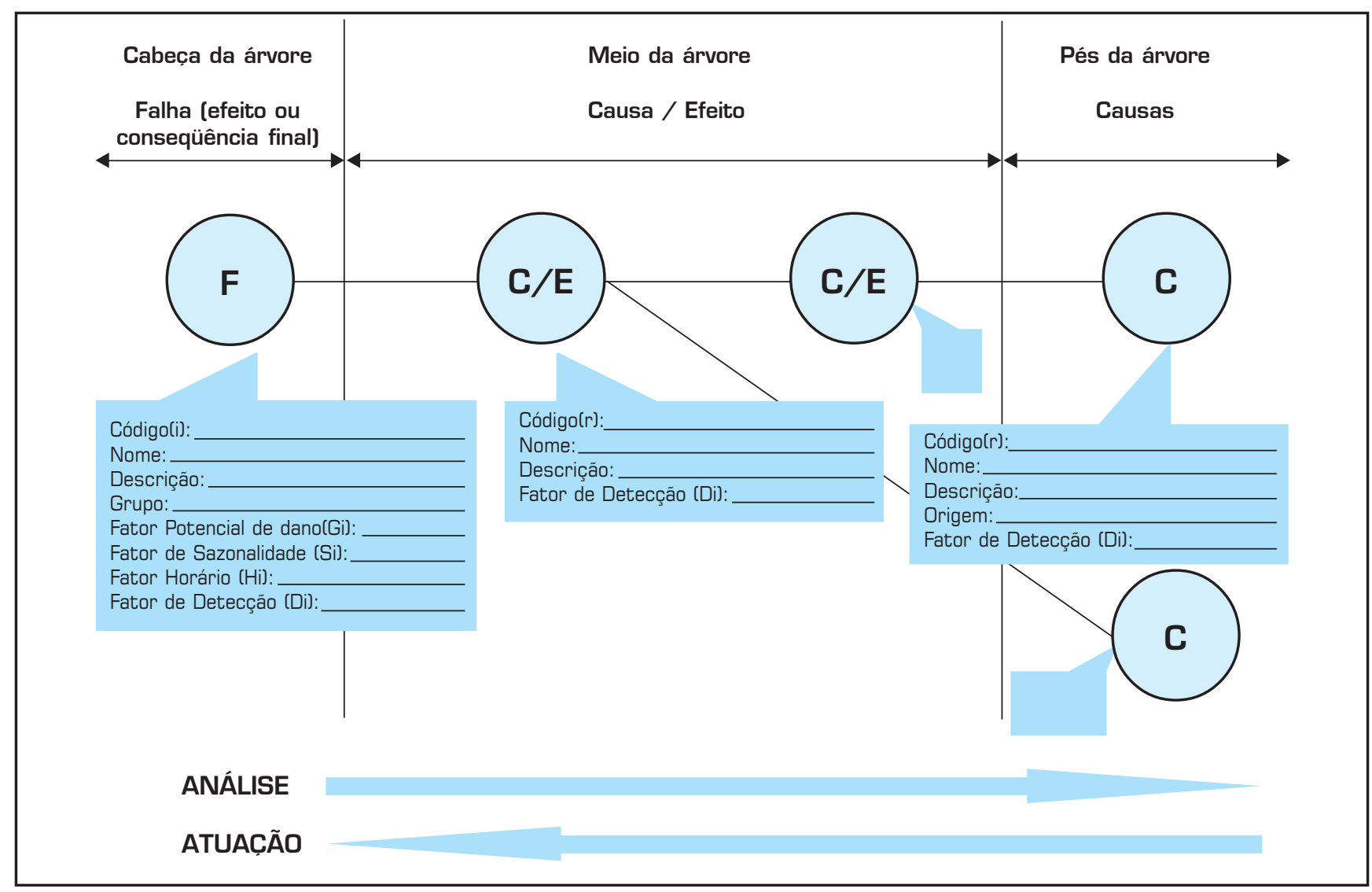

Fonte: Almeida et al. (2004b). 
- Fator de Sazonalidade $\left(\mathrm{S}_{\mathrm{i}}\right)$ : fator que pondera a característica intrínseca da falha referente ao seu potencial de dano, de acordo com períodos sazonais. Pode-se citar como exemplo o período chuvoso, que pode agravar o potencial de dano de uma determinada falha.

- Fator Horário $\left(\mathrm{H}_{\mathrm{i}}\right)$ : fator que pondera o potencial de dano da falha, de acordo com os períodos do dia. Pode-se citar como exemplo a divisão do dia em três períodos: leve, médio e pesado. Esta classificação permite atribuir um peso maior ao dano de uma determinada falha quando esta ocorre no horário "de pico" do sistema.

- Fator de Detecção $\left(\mathrm{D}_{\mathrm{i}}\right)$ : fator que descreve a política de manutenção adotada, ou seja, a avaliação conceitual da política de manutenção vigente do sistema gerador de falhas. Este fator varia de 1 a 9, conforme apresenta a Figura 6. A questão da detecção, assim como o potencial de dano, são retratadas na técnica da Análise dos Efeitos e Modos de Falhas (FMEA - Failure Mode and Effects Analysis) (HELMAN \& ANDERY, 1995).

ii) nó intermediário $(\mathrm{C} / \mathrm{E})$

Nos nós intermediários foram definidos o código (r), nome e descrição, e por fim o Fator de Detecção $\left(D_{\mathrm{r}}\right)$. Este fator depende das facilidades tecnológicas da detecção das partes do sistema sujeitas à falha. Assim como demonstrado na Figura 6, este fator varia de 1 a 9, indicando a probabilidade de detecção da causa antes que ela venha a provocar a falha.

iii) nó causa, pé da árvore $(\mathrm{C})$

Nos nós que representam os pés da árvore foram definidos o código (r), nome e descrição, origem e o fator de detecção $\left(\mathrm{D}_{\mathrm{r}}\right)$. Os grupos de origem da causa foram apresentados na Tabela 1 deste trabalho.
A filosofia do presente projeto é entender como "causa" aquilo que é plausível de intervenção gerencial. Assim, não há sentido em se entender que eventos como "descargas atmosféricas", do grupo de origem "Fenômenos Naturais", sejam considerados como causas anuláveis por ações gerenciais.

A partir desta parametrização e da lógica da árvore, torna-se possível uma análise completa da gênese do problema, partindo da cabeça ao pé da árvore (a jusante), permitindo assim uma atuação gerencial, partindo dos pés à cabeça da árvore (a montante).

As conexões (setas) entre os nós também podem ser parametrizadas, a fim de melhor caracterizar a relação existente entre cada nó. Estas informações também têm a função de evitar que a equipe se perca em futuras análises da árvore, pois mantém o registro explicativo de cada relação causa/efeito.

Após a finalização do diagrama, os participantes da equipe realizaram uma análise da situação retratada e uma revisão. Isto foi importante para aproveitar ao máximo o potencial da ferramenta. Esta verdadeira leitura crítica foi feita movendo-se, sobre o diagrama, no sentido inverso ao da construção.

Os três tipos de conversão do conhecimento que foram utilizados no levantamento das falhas mais ocorridas da empresa também foram utilizados nas etapas de construção das árvores (diagramação) e parametrização. A socialização ocorreu novamente nestas etapas para diagramação e parametrização através das sessões de brainstorming. Os funcionários e acadêmicos contribuíram cada um com seus conhecimentos para a montagem dos diagramas. A combinação ocorreu através da utilização de teorias dos livros, dos documentos da empresa e de normas do setor de energia elétrica. O registro dos diagramas desenvolvi-

Figura 6: Fator de detecção, definido de 1 a 9.

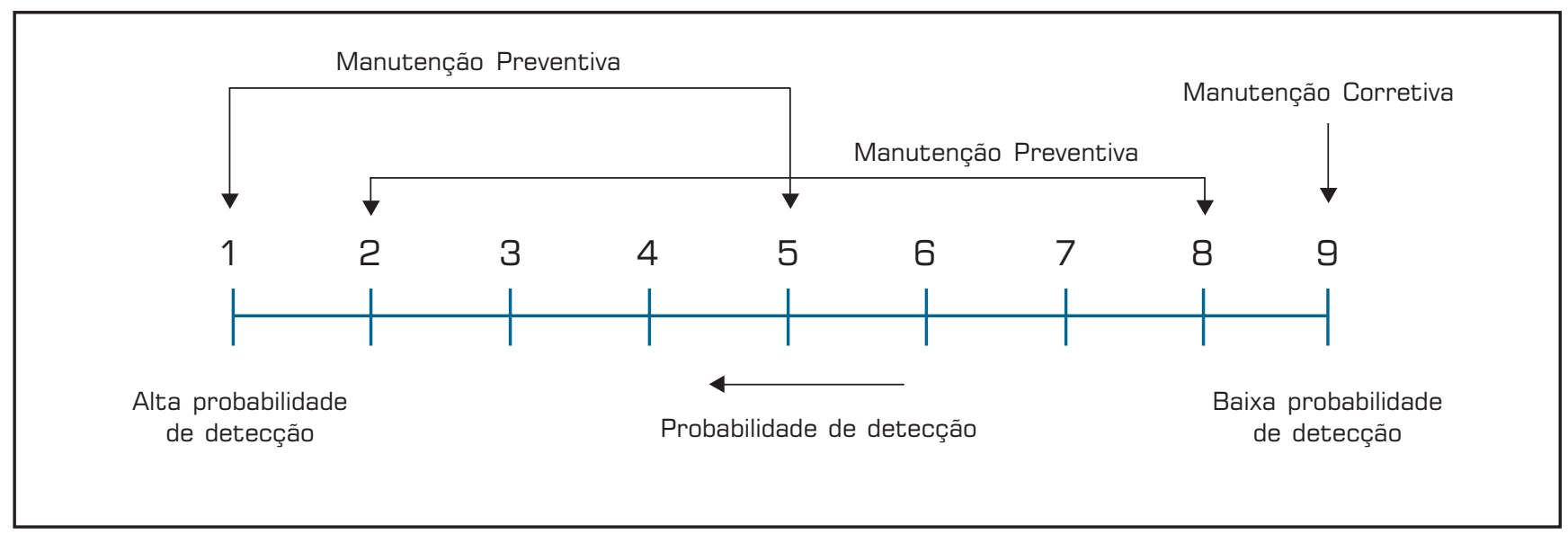

Fonte: Almeida et al. (2004b). 
dos, assim como das informações referentes a eles, caracterizou a externalização.

Durante a fase de intervenção gerencial será utilizada a quarta forma de conversão do conhecimento, a internalização.

Como pode ser observado pela descrição do Modelo de Mapeamento de Falhas, para a construção das árvores foram diagnosticadas, levantadas e criadas muitas informações. Desta forma, foi desenvolvido um modelo de Sistema de Informação, para auxiliar no armazenamento de todas as informações levantadas e também para facilitar o processo de mapeamento.

\section{OPERACIONALIZAC̣̃̃O DO MODELO DE MAPEAMENTO DE FALHAS ATRAVÉS DE UM SISTEMA DE INFORMAC̄ÃO}

O sistema de informação para o desenvolvimento de diagramas de árvores de falhas contempla as informações existentes nos nós (componentes das árvores representados por círculos) sobre a natureza do evento e enfatiza a relação causa-efeito entre as conexões (representada nas árvores por setas) desses nós. Em resumo, este sistema de informação teve como objetivo a captura dos conhecimentos dos funcionários da empresa, de modo a registrá-los em um banco de dados dinâmico.

O software de mapeamento de falhas desenvolvido para auxiliar na confecção dos mapas de causa e efeito, bem como para a inclusão de documentos pertinentes, é ilustrado a seguir.

Como exemplo das informações que o sistema contempla, tem-se a árvore de falhas "Cabo Interrompido", mostrada na Figura 7, que foi extraída do Diagrama de Afinidades das falhas diagnosticadas em uma distribuidora de energia elétrica.

Os nós existentes neste diagrama são representados pelos círculos, e devem conter descrições sobre a natureza do evento. Por exemplo, para o nó "Conexão Inadequada" tem-se a seguinte informação: "Luvas, conectores, emenda e alças pré-formadas: conector inadequado, montagem incorreta (ferramenta ou aperto inadequado)". No sistema proposto esta informação pode ser visualizada conforme mostra a Figura 8.

As conexões existentes no diagrama mostrado na Figura 6 são representadas pelas setas. Estas conexões devem conter informações sobre a relação entre causa e efeito existente entre os nós.

Pode-se citar como exemplo a seguinte situação: entre

Figura 7: Árvore de Falhas para "Cabo Interrompido".

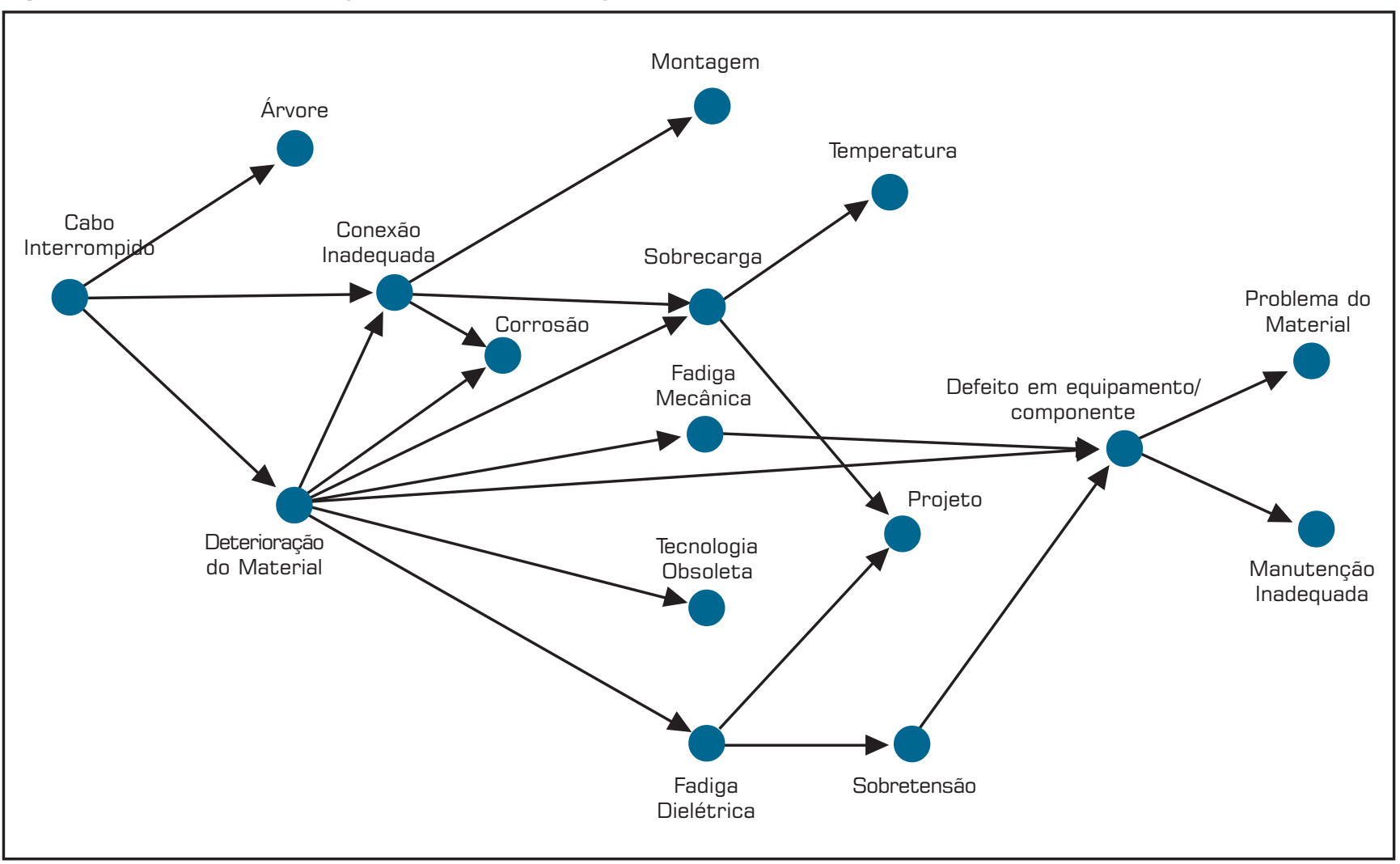


os nós "Cabo Interrompido" e "Conexão Inadequada", tem-se a seguinte informação: "Conexão malfeita ou oxidada, impedindo a passagem de corrente". No sistema proposto esta informação pode ser visualizada conforme mostra a Figura 9.

O modelo de sistema de informação proposto também permite que os usuários armazenem fotos e documentos relativos ao diagrama de árvore de falhas. Para a árvore de falhas "Cabo Interrompido" mostrada anteriormente na Figura 6 tem-se uma relação de fotos mostrada na parte esquerda da Figura 10 e uma relação de documentos mostrada na parte direita desta mesma figura.

A intenção é promover a aprendizagem organizacional, uma vez que as pessoas envolvidas no processo podem consultar essa lista de fotos e documentos a qualquer momento. Desta forma, o conhecimento pode ser preservado e utilizado para treinar futuros funcionários e facilitar o processo de propagação de conhecimento, ou seja, o sistema de informação a serviço da GC.

\section{RELAC̣ÃO ENTRE ANÁLISE DE FALHAS, GESTÃ்O DO CONHECIMENTO E SISTEMAS DE INFORMAC̣̃̃O}

O Quadro 2 representa as três abordagens que foram utilizadas conjuntamente neste trabalho e a relação entre elas. A primeira coluna do quadro representa as diferentes etapas executadas para a análise de falhas. A segunda

Figura 8: Informação contida no nó: "Conexão Inadequada”.

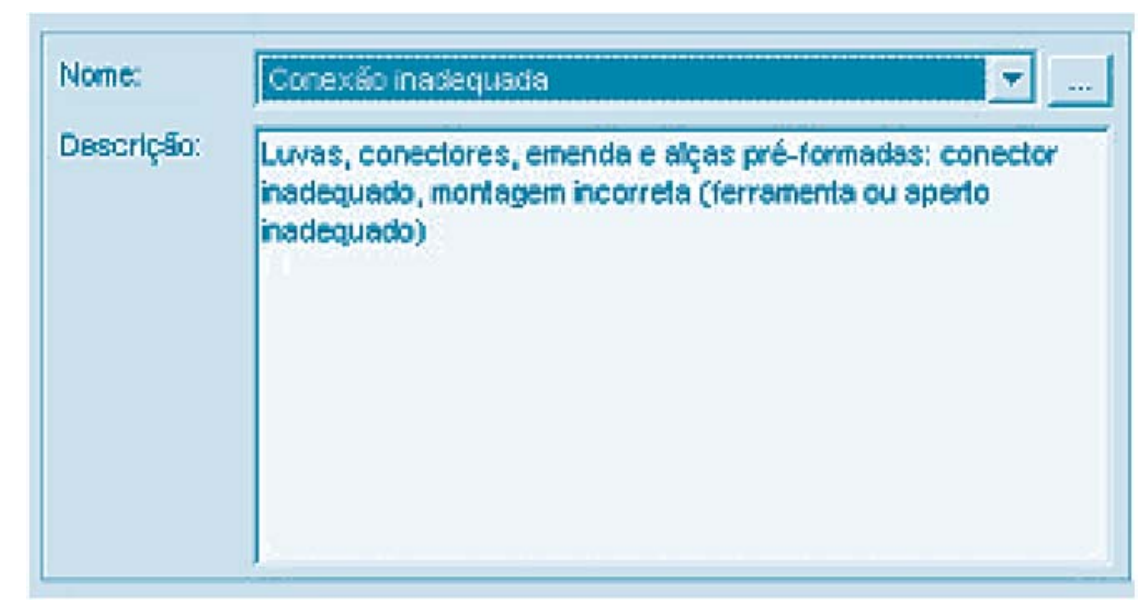

Figura 9: Informação contida na conexão entre os nós: "Cabo Interrompido" e "Conexão Inadequada".

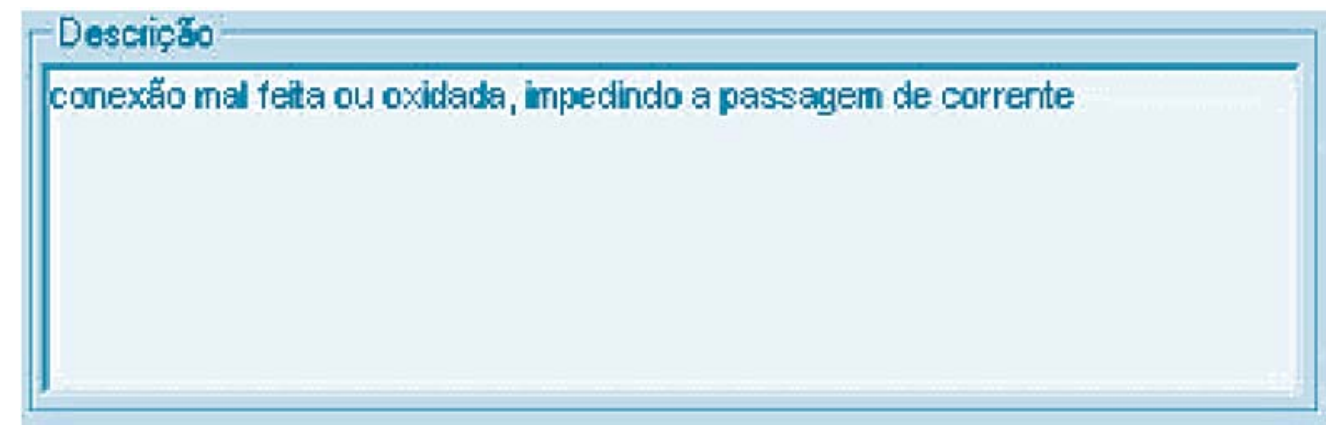




\section{Figura 10: Relação de fotos e documentos para a árvore de falhas: "Cabo Interrompido"}

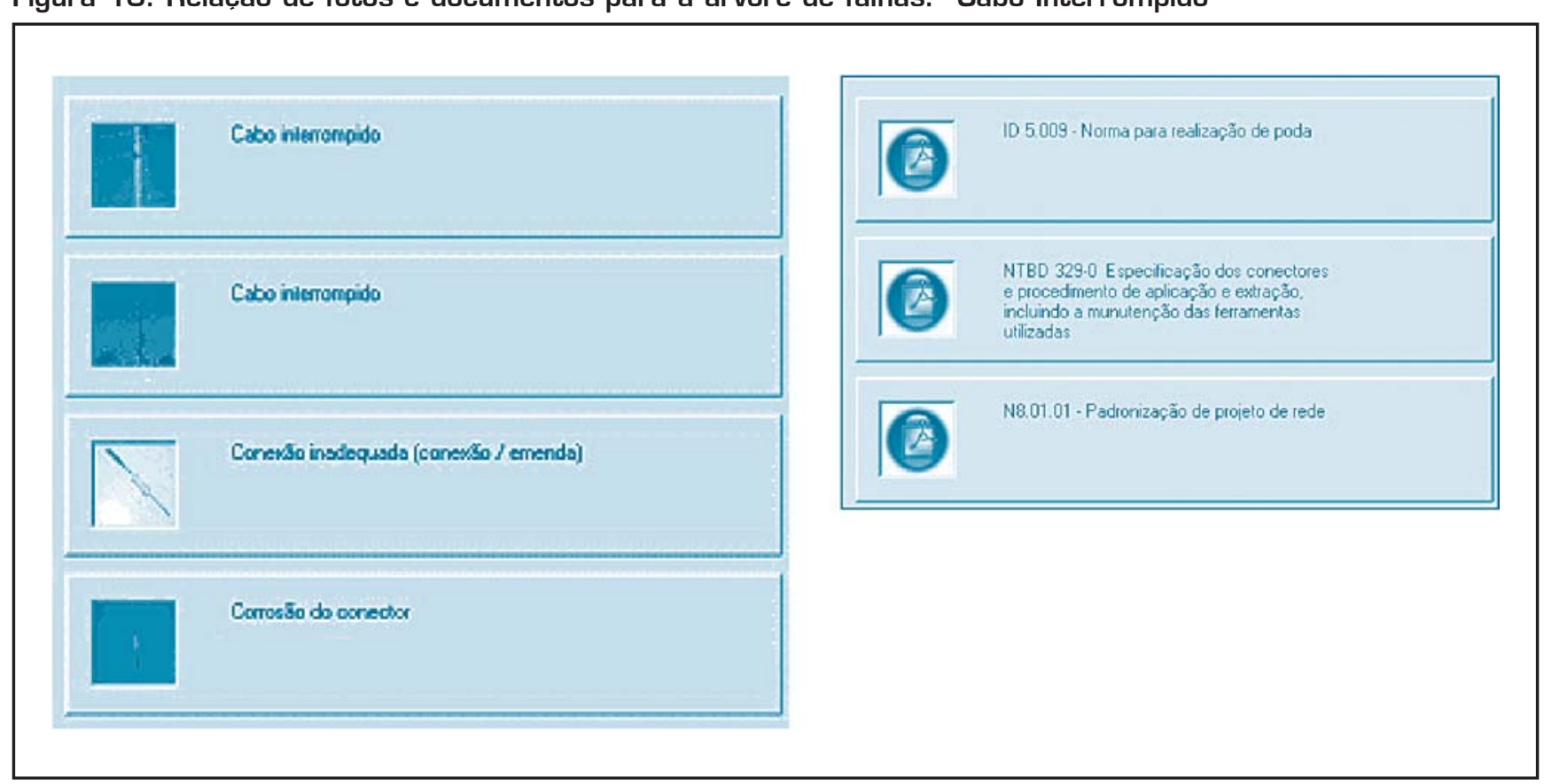

Quadro 2: A dinâmica do Grupo de Análise de Falhas e a Gestão do Conhecimento.

\begin{tabular}{|c|c|c|c|}
\hline & ANÁLISE DE FALHAS & GESTÃO DO CONHECIMENTO & SISTEMAS DE INFORMAÇÃO \\
\hline 1 & Diagnóstico das falhas & $\begin{array}{l}\text { Socialização } \\
\text { Combinação } \\
\text { Externalização } \\
\text { Internalização }\end{array}$ & \\
\hline 2 & Definição dos grupos de falhas & $\begin{array}{l}\text { Socialização } \\
\text { Combinação } \\
\text { Externalização }\end{array}$ & \\
\hline 3 & Construção das árvores & $\begin{array}{l}\text { Socialização } \\
\text { Combinação } \\
\text { Externalização }\end{array}$ & $\begin{array}{l}\text { Captura dos conhecimentos dos funcioná- } \\
\text { rios da empresa, de modo a registrá-los } \\
\text { em um banco de dados dinâmico (software } \\
\text { de mapeamento de falhas). }\end{array}$ \\
\hline 4 & $\begin{array}{l}\text { Definição das origens } \\
\text { das causas }\end{array}$ & $\begin{array}{l}\text { Socialização } \\
\text { Combinação } \\
\text { Externalização } \\
\text { Internalização }\end{array}$ & \\
\hline 5 & $\begin{array}{l}\text { Parametrização dos elos e } \\
\text { conexões }\end{array}$ & $\begin{array}{l}\text { Socialização } \\
\text { Combinação } \\
\text { Externalização }\end{array}$ & $\begin{array}{l}\text { Captura dos conhecimentos dos funcioná- } \\
\text { rios da empresa, de modo a registrá-los } \\
\text { em um banco de dados dinâmico (software } \\
\text { de mapeamento de falhas). }\end{array}$ \\
\hline 6 & $\begin{array}{l}\text { Utilização das árvores } \\
\text { construídas para gestão } \\
\text { das falhas }\end{array}$ & Internalização & $\begin{array}{l}\text { Utilização do conhecimento gerado e que } \\
\text { se encontra no software de mapeamento } \\
\text { de falhas. }\end{array}$ \\
\hline
\end{tabular}

Meio que permitiu e facilitou a captura do conhecimento gerado 
coluna representa as formas de conversão do conhecimento que foram utilizadas em cada etapa da análise de falhas e a relação com o modelo de cinco fases do processo de criação do conhecimento organizacional, mostrado na Figura 2. A terceira coluna mostra em quais etapas da análise de falhas o software de mapeamento foi utilizado, caracterizando o uso de sistemas de informação para análise de falhas.

Explicando mais detalhadamente o Quadro 2, temos o Quadro 3.

Bastante relevante também é a utilização prática dos conhecimentos disponibilizados nas relações de causa e efeito das árvores. Neste contexto, o eletricista da equipe de campo, por melhor que seja seu treinamento, não terá condições de identificar todas as possíveis causas. Assim, premido pela urgência do atendimento e pela complexidade da ocorrência, serão registrados apenas as causas mais aparentes (combinação). Desta forma o software é capaz de destacar as relações biunívocas de falha/causas que serão entendidas pelos profissionais das equipes de atendimento e formalizadas nos relatórios de ocorrências (internalização).

\section{CONCLUSÃO}

O presente artigo apresentou primeiramente um modelo de mapeamento de falhas para aplicação no setor de distribuição de energia elétrica. As falhas que foram mapeadas representam um acervo de informações necessário à excelência da atuação operacional.

Para auxiliar na aplicação do modelo para mapeamento de falhas foi apresentado um sistema de informação através de um software de mapeamento de falhas que mostrou-se apto à Gestão do Conhecimento, ao permitir a inserção de documentos e fotos associados à árvore,

\section{Quadro 3- Explicação do Quadro 2.}

\begin{tabular}{|c|c|}
\hline $\begin{array}{l}\text { ANÁLISE DE } \\
\text { FALHAS }\end{array}$ & \\
\hline 1 & $\begin{array}{l}\text { Socialização (a): compartilhamento de conhecimento individual. } \\
\text { Combinação (c } \rightarrow \mathbf{d} \text { ): uso coletivo do conhecimento formal da empresa. } \\
\text { Internalização }(\mathbf{e} \leftarrow \mathbf{a}) \text { : constatação de uma realidade pouco ou nada conhecida através da observação. } \\
\text { Externalização }(\mathbf{a} \rightarrow \mathbf{b} \rightarrow \mathbf{c}): \text { elaboração do diagnóstico é oficializada (registrada) na condição de } \\
\text { documento formal. }\end{array}$ \\
\hline 2 & $\begin{array}{l}\text { Socialização (a): compartilhamento de conhecimento individual. } \\
\text { Externalização }(\mathbf{a} \rightarrow \mathbf{d}) \text { : discussões que se tornaram modelos (listas). } \\
\text { Combinação }(\mathbf{d} \rightarrow \mathbf{e}) \text { : registro de lista de falhas e sua divulgação. }\end{array}$ \\
\hline 3 & $\begin{array}{l}\text { Socialização (a): compartilhamento de conhecimento individual. } \\
\text { Externalização }(\mathbf{a} \rightarrow \mathbf{b} \rightarrow \mathbf{c} \rightarrow \mathbf{d}): \text { árvores foram concebidas. } \\
\text { Combinação (d } \rightarrow \mathbf{e}): \text { difusão dos modelos (árvores) desenvolvidos. }\end{array}$ \\
\hline 4 & 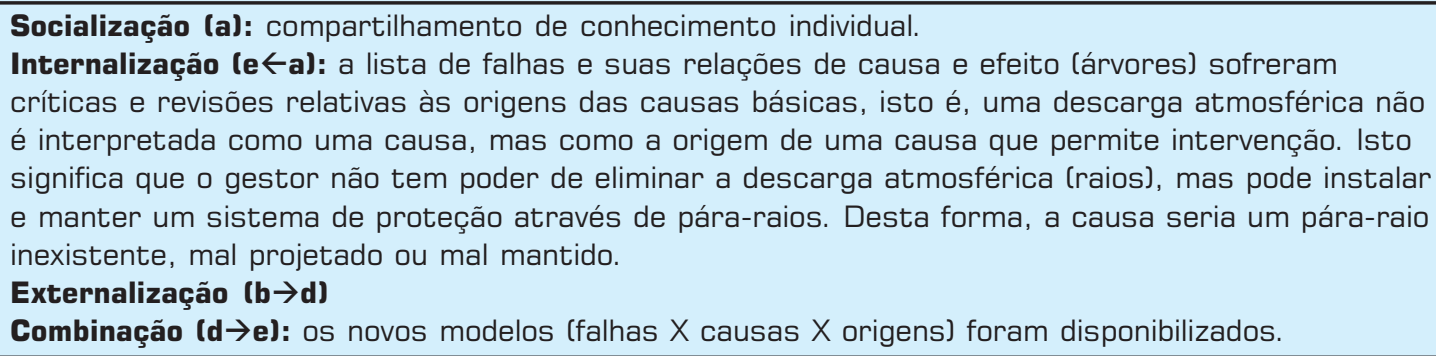 \\
\hline 5 & $\begin{array}{l}\text { Socialização (a): compartilhamento de conhecimento individual. } \\
\text { Externalização }(\mathbf{a} \rightarrow \mathbf{d} \text { ): criação de árvores parametrizadas. } \\
\text { Combinação }(\mathbf{d} \rightarrow \mathbf{e}): \text { formalização de um conhecimento (árvores parametrizadas). } \\
\text { Internalização }(\mathbf{e} \rightarrow \mathbf{a}) \text { : as árvores construídas passaram a ser objeto de discussão com vistas à } \\
\text { inclusão de parâmetros. }\end{array}$ \\
\hline 6 & $\begin{array}{l}\text { Esta etapa caracteriza todos os esforços anteriores. Nela, as árvores criadas serão utilizadas. } \\
\text { Obviamente, no ciclo de conversão do conhecimento, a empresa criará condições para que tais } \\
\text { modelos e padrões lárvores de falhas] possam ser criticados e aprimorados. }\end{array}$ \\
\hline
\end{tabular}

Obs. : Externalização $(b \rightarrow c \rightarrow d)$ se caracteriza onde não há compartilhamento de pensamentos, ou seja, seria baseada na reflexão individual que se normaliza como algo concreto. 
além de possibilitar a manipulação das descrições contidas nos nós e conexões existentes na árvore.

Este modelo de sistema de informação, i. e., o software de mapeamento de falhas, permite que a organização armazene todo o conhecimento gerado na análise da gênese da falha. Da mesma forma que o gestor deve ter acesso a um conjunto de informações para tomada de decisões, eletricistas das equipes de atendimento podem ser treinados a reconhecer falhas, causas e a lógica de conexão, ou seja, e relação de dependência causa/conseqüência. Tal reconhecimento, embora possa não ser possível para todos os elos da árvore, devido às complexidades técnicas que só um especialista pode reconhecer ou tem condições de avaliar, poderão, no entanto, com o devido treinamento, identificar as causas das falhas de maneira fácil e rápida. Salienta-se que parte desta dificuldade se dá pela premência de tempo requerida nas atividades de atendimento de emergências de campo necessárias ao pronto restabelecimento de energia.

Em resumo, esta abordagem sistematiza a documentação técnica disponível na empresa, a qual se encontra normalmente dispersa e não relacionada aos temas que requerem intervenção gerencial, no contexto dos mapas de causa-efeito das falhas que afligem o sistema. Tal abordagem é algo relativamente novo, que não é contemplado nos sistemas de informação e nem nos métodos de mapeamento de falhas (Diagrama Sistemático de Causa e Efeito, FTA e ETA). Desta maneira, o método de mapeamento de falhas proposto neste artigo e utilizado na prática do caso apresentado configura um banco de dados descrito no Diagrama Sistemático de Causa e Efeito das árvores desenvolvidas.

Finalmente, outro aspecto que merece ser ressaltado refere-se às reuniões para o mapeamento das falhas, pela utilização do sistema de informação, o que representou uma excelente oportunidade para a troca de conhecimento entre os profissionais da empresa. O registro resultante de tal experiência e o conhecimento que se explicitou pode ser posteriormente disseminado através da Intranet da organização. Esta dinâmica estimulou a troca e a conversão do conhecimento, o que caracteriza a prática da Gestão do Conhecimento.

\section{Artigo recebido em 11/07/2005 Aprovado para publicação em 02/12/2005}

\section{- Referências Bibliográficas}

ADAMS, E.; FREEMAN, C. Communities of practice: bridging technology and knowledge assessment. Journal of Knowledge Management, v. 4, n. 1, 2000

ALAVI, M.; LEIDNER, D. E. Knowledge management systems: issues, challenges, benefits. Communications of AIS, v.1, n. 7, p. 2-41, 1999.

ALBERTON, Anete. Uma metodologia para auxiliar no gerenciamento de riscos e na seleção de alternativas de investimentos em segurança. Dissertação (Mestrado em Eng. Produção) Programa de Pós-Graduação em Engenharia de Produção, Universidade Federal de Santa Catarina, Florianópolis, SC, 1996.

ALMEIDA; D. A.; FAGUNDES, L. D.; LEAL; F. Metodologia de gestão de falhas para empresas do setor elétrico. In: ENCONTRO NACIONAL DE ENGENHARIA DE PRODUÇÃO (ENEGEP), 2004, Florianópolis / SC Anais. Florianópolis: ENEGEP, 2004a.
ALMEIDA, D. A.; LEAL, F.; ALMEIDA, R.A. Mapeamento do Processo de Formação de Falhas: Uma Aplicação no Setor Elétrico. In: CONGRESSO BRASILEIRO DE ENERGIA (CBE), 10 , Anais....Rio de Janeiro, 2004b.

ANJARD, R. P. Management and planning tools. Training for Quality, 1995, v. 3, n. 2, p. 34-37, 1995.

COMITE DE DISTIBUIÇÂO. Planejamento de Sistemas de Distribuição. v. 1, Editora Campus, 1. ed., Rio de Janeiro, 1982.

COUGHLAN, P.; COGHLAN, D. Action Research-Action research for operations management. International Journal of Operations \& Production Management, v. 22, n. 2, p. 220-240, 2002.
DIKMEN, I.; BIRGONUL, M. T.; KIZILTAS, S. Strategic use of quality function deployment (QFD) in the construction industry. Building and Environment, v. 40 , n.2, p. 245-255, 2004.

FAGUNDES, L. D. Mapeamento de faIhas em concessionária do setor elétrico: Gestão do Conhecimento auxiliando a Gestão da Manutenção. Dissertação (Mestrado em Eng. Produção) Programa de Pós-Graduação em Engenharia de Produção, Universidade Federal de Itajubá, Itajubá, MG, 2005.

FAGUNDES, L. D.; ALMEIDA; D. A. Aplicação da Gestão do Conhecimento para análise de falhas no setor de energia elétrica. In: SEMINÁRIO NACIONAL DE GESTÃO DA INFORMAÇÃO E DO CONHECIMENTO NO SETOR DE ENERGIA ELÉTRICA. Anais. Recife / PE, 2004.
GANIM, A. Setor Elétrico Brasileiro - Aspectos regulamentares e tributários. Editora Canalenergia, 2003.

GLAZIER, Jack D.; POWELL, Ronald R. Qualitative research in information management. Englewood, CO: Libraries Unlimited, 1992. 238 p.

GIL, A. C. Como Elaborar Projetos de Pesquisa. 3. ed. São Paulo: Atlas, 1996. 159 p.

HAMMARBERG, J.; NADJM-TEHRANI, S. Development of Safety-Critical Reconfigurable Hardware with Esterel. Electronic Notes in Theoretical Computer Science 80 (2003). Disponível em: <http://www.elsevier.nl/ locate/entcs/volume80.html $>$.

HE, Z.; STAPLES, G.; ROSS, M.; COURT, I. Fourteen Japanese quality tools in software process improvement. The TQM Magazine, v. 8 , n. 4, p. 40-44, 1996. 


\section{- Referências Bibliográficas}

HELMAN H., ANDERY, P. R. P. Análise de Falhas. Aplicação de FMEA e FTA. Belo Horizonte: Editora Fundação Cristiano Ottoni, 156 p., 1995.

IEC 50 (191). International Electrotechnical Vocabulary. Chapter 191 - Dependability and quality of service. Int. Electrotechnical Commission, Geneva, 1990.

KARSAK, E. E.; SOZER, S.; ALPTEKIN, E., 2002. Product planning in quality function deployment using combined analytic network process and goal programming approach. Computers \& Industrial Engineering. vol. 44 , n. 1 , p. $171-190$

LAUDON, K. C.; LAUDON L. P. Management Information Systems: Managing the Digital Firm, 8. ed., New Jersey, 2004 .
LEITE, Valéria Fonseca. Gestão do Conhecimento em Empresas de Itajubá: Um Estudo Exploratório. Dissertação (Mestrado em Eng. Produção) Programa de Pós-Graduação em Engenharia de Producão, Universidade Federal de Itajubá, Itajubá, MG, 2001.

MIZUNO, S. Gerência para melhoria da Qualidade - As sete novas ferramentas de controle da Qualidade. Editora LTC, 1993.

NONAKA, Ikujiro. TAKEUCHI, Hirotaka. Criação de Conhecimento na Empresa. Como as empresas Japonesas geram a dinâmica da inovação. Rio de Janeiro: Campus, 1997.

NUNES, E. L., 2001. Manutenção Centrada em Confiabilidade (MCC): aná lise da implantação em uma sistemática de manutenção preventiva consolidada. Dissertação (Mestrado em Eng. Pro- dução) Programa de Pós-Graduação em Engenharia de Produção, Universidade Federal de Santa Catarina, Florianópolis, SC.

O'BRIEN, J. A. Sistemas de Informacão e as Decisões Gerenciais na Era da Internet. Saraiva, 2002.

RAUSAND, M. \& OIEN, K. (1996) The basic concepts of failure analysis. Reliability Engineering and System. Safety, n. 53, p. 73-83, 1996.

SCHOCKLEY III, W.; Planning for Knowledge Management. Quality Progress, March 2000, p. 57-62.

SILVA, E. L: MENEZES, E. M. Metodologia da Pesquisa e Elaboração de Dissertação. 2. ed. Florianópolis: LED/ PPGEP/UFSC, 2001.
SILVEIRA, Antônio Augusto. Gestão do conhecimento como ênfase na aprendizagem organizacional: um estudo de multicaso no contexto bancário. Dissertação (Mestrado em Eng. Produção) Programa de PósGraduação em Engenharia de Produção, Universidade Federal de Itajubá, Itajubá, MG, Agosto de 2004.

SRDOC, ALIRA; SLUGA, ALOJZIJ; BRATKO, Ivan International Journal of Quality \& Reliability Management, v. 22 n. 3,2005 , p. $278-302$

SVEIBY, Karl Erik. A Nova Riqueza das Organizações: gerenciando e avaliando patrimônios de conhecimento. Rio de Janeiro: Campus, 1998.

XU, JUN; QUADDUS, MOHAMMED. Adoption and diffusion of knowledge management systems: an Australian survey. Journal of Management Development, v. 24, n. 4, 2005. p. 335361.

\section{- Sobre os autores}

\section{Dagoberto Alves de Almeida}

$\mathrm{PhD}$ in Manufacturing System Engineering (University of Cranfield - UK)

Professor do Instituto de Engenharia de Produção e Gestão - Universidade Federal de Itajubá

Caixa Postal 50 - CEP 37500-903 - Itajubá - MG

Telefone: (35) 3629-1159, FAX: (35) 3622-3596

E-mail: dagoberto@unifei.edu.br

\section{Fabiano Leal}

M.Sc. em Engenharia de Produção (Universidade Federal de Itajubá)

Professor do Instituto de Engenharia de Produção e Gestão - Universidade Federal de Itajubá

Caixa Postal 50 - CEP 37500-903 - Itajubá - MG

Telefone: (35) 3629-1297, FAX: (35) 3622-3596

E-mail: fleal@unifei.edu.br

\section{Alexandre Ferreira de Pinho}

M.Sc. em Engenharia de Produção (Universidade Federal de Itajubá)

Professor do Instituto de Engenharia de Produção e Gestão - Universidade Federal de Itajubá

Caixa Postal 50 - CEP 37500-903 - Itajubá - MG

Telefone: (35) 3629-1297, FAX: (35) 3622-3596

E-mail: pinho@unifei.edu.br

\section{Liliane Dolores Fagundes}

M.Sc. em Engenharia de Produção (Universidade Federal de Itajubá)

Pesquisadora do Instituto de Engenharia de Produção e Gestão - Universidade Federal de Itajubá

Caixa Postal 50 - CEP 37500-903 - Itajubá - MG

Telefone: (35) 3629-1297, FAX: (35) 3622-3596

E-mail: liliane@unifei.edu.br 